FINAL REPORT

\title{
CONVECTION HEAT TRANSFER IN THREE-DIMENSIONAL TURBULENT SEPARATED/REATTACHED FLOWS
}

\author{
Prepared for Department of Energy - Office of Basic Energy Sciences \\ Under Grant \# DE-FG02-03ER46067 \\ Department of Mechanical and Aerospace Engineering \\ University of Missouri-Rolla \\ Rolla, Missouri 65401
}

October 2007 


\begin{abstract}
$\underline{\text { Abstract }}$
The measurements and the simulation of convective heat transfer in separated flow have been a challenge to researchers for many years. Measurements have been limited to twodimensional flow and simulations failed to predict accurately turbulent heat transfer in the separated and reattached flow region (prediction are higher than measurements by more than 50\%). A coordinated experimental and numerical effort has been initiated under this grant for examining the momentum and thermal transport in three-dimensional separated and reattached flow in an effort to provide new measurements that can be used for benchmarking and for improving the simulation capabilities of 3-D convection in separated/reattached flow regime. High-resolution and non-invasive measurements techniques are developed and employed in this study to quantify the magnitude and the behavior of the three velocity components and the resulting convective heat transfer. In addition, simulation capabilities are developed and employed for improving the simulation of 3-D convective separated/reattached flow. Such basic measurements and simulation capabilities are needed for improving the design and performance evaluation of complex (3-D) heat exchanging equipment.
\end{abstract}

Three-dimensional (3-D) convective air flow adjacent to backward-facing step in rectangular channel is selected for the experimental component of this study. This geometry is simple but it exhibits all the complexities that appear in any other separated/reattached flow, thus making the results generated in this study applicable to any other separated and reattached flow. Boundary conditions, inflow, outflow, and wall thermal treatment in this geometry can be well measured and controlled. The geometry can be constructed with optical access for non-intrusive measurements of the flow and thermal fields. A three-component laser Doppler velocimeter (LDV) is employed to measure simultaneously the three-velocity components and their turbulent fluctuations. Infrared thermography is utilized to measure the wall temperature and that information is used to determine the local convective heat transfer coefficient. FLUENT - CFD code is used as the platform in the simulation effort and User Defined Functions are developed for incorporating advanced turbulence models into this simulation code. Predictions of 3-D turbulent convection in separated flow, using the developed simulation capabilities under this grant, compared well with measured results.

Results from the above research can be found in the seventeen refereed journal articles, and thirteen refereed publications and presentations in conference proceedings that have been published by the PI during the this grant period. The research effort is still going on and several publications are being prepared for reporting recent results.

\title{
$\underline{\text { Project Description }}$
}

A four years project (starting August 1, 2003 and ending July 31, 2007) was proposed to DOE for a total of $\$ 533,676$ for initiating a coordinated experimental and numerical effort for examining momentum and thermal transport in three-dimensional (3-D) separated and reattached flow. DOE funded only the first two years of the proposed four years project (August 1, 2003 through July 31, 2005) for the sum of $\$ 258,966$. Two one year no cost extension requests were granted for the period of August 1, 2005 through July 31, 2006, and for the period of August 1, 
2006 through July 31, 2007. The following summarizes the facilities and the simulation capabilities that were developed as a result of this grant.

\section{$\underline{\text { Facilities }}$}

A vertical open air tunnel was built specifically for this project and it is shown schematically in Fig. 1. The inlet section of the tunnel consists of a diverging section, a straight section, and a converging section. The diverging section is packed with steel wool to remove any large oil particles from the seeded air, and the straight section is packed with honeycomb material for straightening the flow. The converging section has an area ratio of 10:1 and the smaller section connects directly to the upstream section of the tunnel. This configuration insured the developments of fully developed, low turbulence airflow at the edge of the backward-facing step. An aluminum frame supported the tunnel in its vertical orientation. The air tunnel uses a high-pressure air tank to supply the air flow, an upstream section for developing the inlet air flow, and a downstream section that forms the sudden expansion in geometry and provides a backward-facing step of $1.0 \mathrm{~cm}$ in height $(S)$ and $8.0 \mathrm{~cm}$ wide $(W)$. The tunnel is constructed from Plexiglas sheets of $0.95 \mathrm{~cm}$ thick that are machined and assembled to form the desired geometry. The two sidewalls of the test section are made of $0.6 \mathrm{~cm}$ thick optical glass to facilitate flow visualizations and LDV measurements. The upstream section of the air tunnel has a cross section of $0.98 \mathrm{~cm}$ height $(h)$ and $8.0 \mathrm{~cm}$ wide, and it is $200 \mathrm{~cm}$ long. This length is sufficient to ensure fully developed airflow at the step. The downstream section of the air tunnel has a cross section of $1.98 \mathrm{~cm}$ height $(H)$ by $8.0 \mathrm{~cm}$ wide and it is $100 \mathrm{~cm}$ long. This length allows the establishment of fully developed flow downstream from the step at the exit section of the tunnel. The test section has an expansion ratio $(E R=H /(H-h))$ of 2.02:1 with an aspect ratio $(A R=W / S)$ of 8 at the step. The air that is supplied to the tunnel originates in a large high pressure air tank and passes through pressure regulation system providing a constant flow rate, with less than $1 \%$ variation, through the tunnel. A fraction of the inlet airflow is bypassed through six jet atomizers and that air stream is seeded with Olive oil particles having a mean diameter of less than $0.6 \mu \mathrm{m}$. The seeded fraction of the airflow is mixed with the unseeded fraction in a large chamber at the inlet of the tunnel, and that mixture form the seeded air stream that flows through the test section of the tunnel. Details of the tunnel's geometry, construction, air flow rates, seeding procedure of air flow for LDV measurements, and its general capabilities and instrumentation can be found in some of the attached publications (see Journal publication \# 5).

A fiber optics three-component laser Doppler velocimeter (LDV) in a back-scattering mode is used to measure the distributions of the three velocity components and their turbulent fluctuations simultaneously, and the boundaries of the recirculation regions that develop downstream from the sudden expansion. The LDV system is a standard six-beam, dual-axis system with a 3W water-cooled Argon-Ion laser and the required transmitting optics. The developing Doppler bursts are processed using Fourier transform analyzers and appropriate software. The measuring probe volume of the LDV system can be moved to within $0.01 \mathrm{~cm}$ from any desired location in the flow field by a 3-D traverse mechanism that is located adjacent to the tunnel. The traverse mechanism and the processing of the Doppler signals are controlled by a personal computer. The wind tunnel is placed in a vertical orientation to permit future studies on how the buoyancy force affects the flow and the heat transfer in this 3-D geometry. 


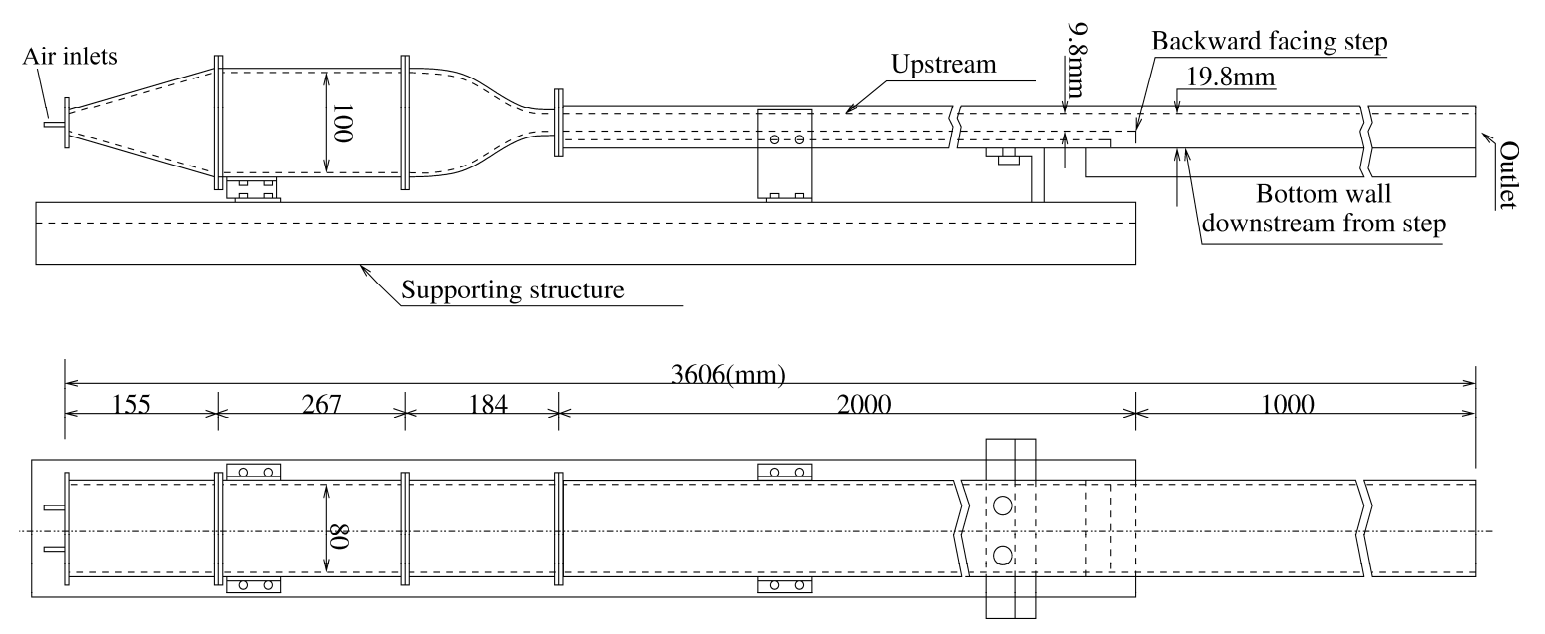

Fig. 1 Schematic of air tunnel

The stepped wall (downstream from the backward-facing step) is constructed for use as a heated surface that is receiving uniform and constant heat flux. This is accomplished by imbedding in that surface a thin film electric heater that is flush with the surface and is supplied by a DC power supply. The imbedded heating element in that electric heater is densely packed and uniformly distributed over its surface to simulate a uniform flux heating condition. Thermocouples are imbedded below the heater surface for temperature measurements, and the back side of that surface was well insulated by a thick Styrofoam sheet. Conduction loss from the back of the heated surface is calibrated by imbedding two thermocouples at a specified distance from each other. Current and voltage measurements are made to determine the level of the heat flux that is supplied to the surface. Zinc Selenide optical window is installed in the surface facing the heated surface in the air tunnel to facilitate the use of infrared thermography for the non-intrusive dynamic measurements of the heated surface temperature that is exposed to the convective flow.

Infrared camera, that is taking images through the Zinc Selenide optical window which is installed in the air tunnel's wall, is used to measure the dynamic surface temperature of the heated surface that is exposed to the convective flow in the air tunnel. The system is fully computerized for image acquisition, display, direct-digitization, recording, and processing of surface temperature distribution. This infrared camera has a built-in FOV (Field of View) of $24^{\circ}$ by $18^{\circ}$, a minimum focus distance of $0.5 \mathrm{~m}$, a frame-rate of $5-7 \mathrm{~Hz}$, and wavelength bandwidth between 7.5 and $13 \mu \mathrm{m}$. The image-processing software provides thermal profiles and gradients across the surface, temperature frequency histograms in a given area, temperature differences from different images, and image filtering and zooming. Surface emissivity and the transmisivity of the optical window are dynamically calibrated during the experiment by using imbedded thermocouples at specific locations below the heated surface. 


\section{Modeling and simulations}

FLUENT - CFD code is used as the platform in the simulation effort of this research project. This computational platform provides access to meshing schemes, and mathematical software, with input and output that can be easily linked electronically to other processing devices. The code has good documentations and provides access to modifications by the user through the use of User Defined Functions. For example, newly developed models by a research team for a particular application can be incorporated into this computational platform by writing User Defined Functions (computer subroutines) for this model and inserting it into this general platform. This computational code and this form of simulation are also heavily utilized by industry.

The FLUENT - CFD code does not include recently developed turbulence models and these recently developed turbulence models have not been applied or tested on three-dimensional convective separated flow. The turbulence models that are part of this code at this time fail to predict accurately the size of the measured recirculation regions in turbulent separated flow and also fail to predict accurately the measured heat transfer in 2-D separated flow, providing errors of greater than $50 \%$. The recent turbulence models improve significantly these 2-D predictions but they are not included in the FLUENT - CFD code and they have not been validated for 3-D separated flow. Part of this research effort is to develop User Define Functions for the recently developed turbulence models and incorporate these subroutines into the computational platform of the FLUENT - CFD code. This newly developed capability in the FLUENT - CFD code will be tested and validated and then used in simulating and examining measured results. This will also provide the capability of testing and possibly validating the use of these recent turbulence models on three-dimensional turbulent separated convective flows.

\section{$\underline{\text { Results }}$}

Results from the above research can be found in the seventeen refereed journal articles, and thirteen refereed publications and presentations in conference proceedings that have been published by the PI during the this grant period. The modeling and the simulation effort has been completed and several publications have already appeared on the subject with few more under preparation. The experimental effort is still going on and several publications are being prepared for reporting recent measured results and coupling them with the simulation part of this research. The measurements of the three velocity components in the 3-D separated flow adjacent to back-ward facing step have been completed. These LDV measurements were used to calculate the mean velocity components (three components, $u, v$ and $w)$, the normal stresses $\left(\overline{u^{\prime 2}}\right.$, $\left.\overline{v^{\prime 2}}, \overline{w^{\prime 2}}\right)$, and the shear stresses $\left(\overline{u^{\prime} v^{\prime}}, \overline{v^{\prime} w^{\prime}}, \overline{w^{\prime} u^{\prime}}\right)$. Some of these results have published and the rest are being prepared for journal publication. Measurements of the heat transfer are still in progress and should be completed by the end of this year. Data are being taken by the infrared camera and surface temperature distributions of the heated and instrumented surface (the stepped wall downstream from the step) are being deduced from the infrared images that are being captured through the Zinc Selenide window of the air tunnel. These results are being prepared for journal publication. 


\section{Publications:}

A list of publications by the PI during the four year period of this grant is provided below. Copies can be provided upon request.

\section{a) Journal publications:}

1) J. H. Nie, and B. F. Armaly, "Buoyancy Effects on Three-Dimensional Convection Flow Adjacent to Backward-Facing Step,” Journal of Thermophysics and Heat Transfer, Vol. 17, No. 1, pp. 122-126, 2003.

2) J. H. Nie, and B. F. Armaly, "Reattachment of Three-Dimensional Flow Adjacent to Backward-Facing Step,” Journal of Heat Transfer, Vol. 125, N0. 2, pp. 422-428, 2003.

3) B. F. Armaly, A. Li, and J. H. Nie, "Measurements in Three-Dimensional Laminar Separated Flow,” International Heat and Mass Transfer Journal, Vol. 46, pp. 3573-3582, 2003.

4) J. H. Nie, B. F. Armaly, W. Q. Tao, and Q. W. Wang, "Measurements of ThreeDimensional Turbulent Air Flow in the Exit Head Section of a Heat Exchanger," Journal of Fluid Engineering, Vol. 126, pp. 72-80, 2004.

5) J. H. Nie, and B. F. Armaly, "Reverse Flow Regions in Three-Dimensional BackwardFacing Step,” International Journal of Heat and Mass Transfer, Vol. 47, pp. 4713-4720, 2004.

6) H. I. Abu-Mulaweh, B. F. Armaly, and T. S. Chen, "Effects of Free Stream Velocity on Turbulent Natural Convection Flow,” Experimental Heat Transfer Journal, Vol. 17, pp. 261-279, 2004.

7) J. H. Nie, and B. F. Armaly, “Convection in Laminar Three-Dimensional Separated Flow," International Journal of Heat and Mass Transfer, Vol. 47, pp.5407-5416, 2004.

8) J. H. Nie, and B. F. Armaly, "Three-Dimensional Forced Convection in Plane Symmetric Sudden Expansion,” Journal of Heat Transfer, Vol.126, pp. 836 - 839, 2004.

9) M. Thiruvengadam, J. H. Nie, and B. F. Armaly, "Bifurcated Three-Dimensional Convection in Plane Symmetric Sudden Expansion," International Journal of Heat and Mass Transfer, Vol. 48/15, pp. 3128-3139, 2005.

10) Y. T. Chen, J H. Nie, B. F. Armaly, and H. T. Hsieh, “Turbulent Separated Convection Flow Adjacent to Backward-Facing Step-Effects of Step Height,” International Journal of Heat and Mass Transfer, Vol. 49, pp. 3670-3680, 2006. 
11) M. Thiruvengadam, B. F. Armaly, and J. A. Drallmeier, "Three-Dimensional Mixed Convection in Plane Symmetric-Sudden Expansion: Bifurcated Flow Regime," ASME Journal of Heat Transfer, Vol. 129, pp. 819 - 826, 2007.

12) Y. T. Chen, J. H. Nie, B. F. Armaly, H. T. Hsieh, and R. F. Boehm, "Developing Turbulent Forced Convection in Two-Dimensional Duct,” ASME Journal of Heat Transfer, Vol. 129, pp. 1295 - 1299, 2007.

13) M. Thiruvengadam, B. F. Armaly, and J. A. Drallmeier, "Shear Driven Liquid Film in a Duct” ASME Fluid Engineering Journal, 2007 (in press).

14) H. Lan, M. Friedrich, B. F. Armaly, and J. A. Drallmeier, "Simulation and Measurements of 3-D Shear Driven Thin Liquid Film Flow in a Duct," Submitted for possible publication in the International Journal of Heat and Fluid Flow, (July 2007)

15) M. Friedrich, H. Lan, J. A. Drallmeier, and B. F. Armaly, "A Separation Criterion with Experimental Validation for Shear-driven Films in separated Flows," Submitted for possible publication in the ASME Fluid Engineering Journal, August 2007.

16) H. Lan, B. F. Armaly, J. A. Drallmeier, "Turbulent Forced Convection in a Plane Asymmetric Diffuser-Effect of Diffuser Angle,” Submitted for possible publication in the ASME Heat Transfer Journal, September 2007.

17) M. Thiruvengadam, B. F. Armaly and J. A. Drallmeier, "Three Dimensional Mixed Convection in Plane Symmetric-Sudden Expansion: Symmetric Flow Regime,” Submitted for possible publication in the International Heat and Mass Transfer Journal, September 07.

18) H. Lan, B. F. Armaly, J. A. Drallmeier, "Three-Dimensional Simulation of Turbulent Forced Convection in a Duct with Backward-Facing Step - Using $k-\zeta-f$ Turbulence model," In preparation to submit for possible publication in the International Heat and Mass Transfer Journal, November 07.

19) M. Thiruvengadam, B. F. Armaly and J. A. Drallmeier, "Measurements in Turbulent ThreeDimensional Separated Flow Adjacent to Backward-Facing Step,” In preparation to submit for possible publication in the International Heat and Mass Transfer Journal, December 07.

20) H. Lan, M. Thiruvengadam, B. F. Armaly and J. A. Drallmeier, "Measurements and simulation of Turbulent Three-Dimensional Forced Convection Adjacent to BackwardFacing Step,” In preparation to submit for possible publication in the International Heat and Mass Transfer Journal, January 08.

\section{b) Refereed published conference presentations :}

1. H. I. Abu-Mulaweh, B. F. Armaly, and T. S. Chen, "Measurements of Turbulent Mixed Convection Flow over a Vertical Forward-Facing Step," Proceedings of the 2003 ASME Summer Heat Transfer Conference, ASME-HT2003-47088, Las Vegas, Nevada, July 21- 
23, 2003.

2. J. H. Nie, and B. F. Armaly, "Three-Dimensional Forced Convection Flow Adjacent to Symmetric Backward-Facing Step” Proceeding of IMECE-2003. ASME-IMECE200341428, in Washington, DC, Nov. 15-22, 2003.

3. J. H. Nie, and B. F. Armaly, "Three-Dimensional Forced Convection Adjacent to Backward Facing Step" Proceedings of the $4^{\text {th }}$ International Symposium on Turbulence, Heat and Mass Transfer, Turbulent Heat and Mass Transfer 4, (K. Hanjalic, Y. Nagano, and M. Tummers, Editors), Begell House Inc., pp. 723-730, 2003.

4. Y. P. Wang, M. Thiruvengadam, J. A. Drallmeier, and B. F. Armaly, "A Comparison of Models for Shear-Driven Liquid Film Separated Around a Corner" Proceedings of the $18^{\text {th }}$ Annual Conference on Liquid Atomization and Spray Systems, Irvine, CA, May 2005.

5. M. Thiruvengadam, B. F. Armaly, and J. A. Drallmeier, "Effects of Buoyancy on flow Bifurcation and Heat Transfer in three-Dimensional Plane Symmetric-Sudden Expansion" Proceedings of the $13^{\text {th }}$ International Heat Transfer Conference, edited by Graham de Vahl Davis and Eddie Leonard, Begell House Inc., Paper \# MCV-07, Sydney, Australia, August 2006.

6. M. A. Friedrich, H. Lan, J. A. Drallmeier, and B. F. Armaly, "Characterization of Sheardriven Liquid Film Separation and Break-up at a Sharp Corner" Proceedings of the $19^{\text {th }}$ Annual Conference on Liquid Atomization and Spray Systems, Toronto, Canada, May 2006.

7. H. Lan, M. A. Friedrich, B. F. Armaly, and J. A Drallmeier, "Three-Dimensional Shear Driven Thin Liquid Film in a Duct", Proceedings of the International Mechanical Engineering Congress and Exposition, Paper \# IMECE2006-15113, Chicago, IL, November 2006.

8. M. Thiruvengadam, B. F. Armaly, and J. A Drallmeier, "Shear Driven Liquid Film in a Duct: Comparison with Measured Results", Proceedings of the International Mechanical Engineering Congress and Exposition, Paper \# IMECE2006-14793, Chicago, IL, November 2006.

9. M. A. Friedrich, N. E. Wilke, H. Lan, J. A. Drallmeier, and B. F. Armaly, "Development of Non-intrusive Film Thickness Measurement Technique for Dynamic Shear-driven Thin Liquid Films," Proceedings of the $20^{\text {th }}$ Annual Conference on Liquid Atomization and Spray Systems, Chicago, IL, May 2007.

10. M. A. Friedrich, J. A. Drallmeier, and B. F. Armaly, "Effects of an induced Perturbation on the Interaction of Separated Gas Flow and Shear-driven Thin Liquid Films," Proceedings of the $20^{\text {th }}$ Annual Conference on Liquid Atomization and Spray Systems, Chicago, IL, May 2007.

11. M. A. Friedrich, H. Lan, N. E. Wilke, J. A. Drallmeier, and B. F. Armaly, "Film Separation 
Criterion with Experimental Validation for Dynamic Shear-driven Thin Liquid Films in Separated Gas Flows," Proceedings of the $20^{\text {th }}$ Annual Conference on Liquid Atomization and Spray Systems, Chicago, IL, May 2007.

12. M. Thiruvengadam, B. F. Armaly, and J. A Drallmeier, "Mixed Convection in Plane Symmetric Sudden Expansion," Proceedings of the $5^{\text {th }}$ International Conference on Heat Transfer, Fluid Mechanics, and Thermodynamics, HEFAT 2007, paper \# TM1, Sun City, South Africa, July 2007.

13. H. Lan, B. F. Armaly, and J. A Drallmeier, "Turbulent Convection in Plane Asymmetric Sudden Expansion”, Proceedings of the International Mechanical Engineering Congress and Exposition, Paper\#IMECE2007-42103, Seattle, WA, November 2007.

\section{List of Personnel:}

The PI, one Post Doctoral Fellow, and two Ph.D. students contributed to the research effort. Dr. Jianhu Nie served as the Post Doctoral Fellow and Mr. Magesh Thiruvengadam and Mr. Hai Lan served as the Ph.D. Candidates on this grant. The following is a short biography for each.

1. Name: Jianhu Nie

Title: Post Doctoral Fellow

Citizenship: China, with H1 Visa

Education: B.S. in Mechanical Engineering, University of Petroleum (East China), 1995.

Ph.D. in Power and Engineering Thermophysics, Xi'an Jiaotong University, 2000

Post Doctor Fellow: University of Missouri - Rolla, 2000 - 2005.

Research Interest: Convective heat transfer, and advanced numerical methods for heat transfer and fluid flows.

Current Status: Serving as a faculty member at the University of Nevada, Las Vegas.

2. Name: Magesh Thiruvengadam

Title: Ph.D. Candidate

Citizenship: India, with student Visa

Education: B.S. in Mechanical Engineering, Anna University, Chennai, India, 1998

M.S. in Mechanical Engineering, Indian Institute of Technology - Madras, India, 2001

Ph.D. in Mechanical Engineering, University of Missouri-Rolla, (in progress and expected to graduate in December 2007).

Research Interest: Convection Heat Transfer, Turbulence Measurements, and CFD.

Current Status: Will be completing his Ph.D. program this semester and will graduate in December 2007. He is seeking employment with an industrial firm.

3. Name: Hai Lan

Title: Ph.D. Candidate

Citizenship: China, with student Visa

Education: B.S. in Mechanical Engineering, Ho Hai University, China, 2001

M.S. in Mechanical Engineering, Northwestern Poly-technical University, China, 2004 
Ph.D. in Mechanical Engineering, University of Missouri-Rolla, (in progress and expected to graduate in May 2008).

Research Interest: Convection Heat Transfer, Turbulence Modeling, and CFD.

Current Status: Will be completing his Ph.D. program next semester and will graduate in May 2008. He is seeking employment with an industrial firm. 